\title{
The effects of migration on the detection of geographic differences in disease risk
}

\author{
Peter A. Rogerson*, Daikwon Han \\ Department of Geography, National Center for Geographic Information and Analysis, Wilkeson Hall, University at Buffalo, \\ Buffalo, NY 14261, USA
}

\begin{abstract}
Human migration can make it more difficult to detect geographic differences in disease risk because of the spatial diffusion of people originally exposed in a given geographic area. There are also situations where migration can facilitate the detection of disease attributable to environmental hazards. This paper assesses the effects that migration has on the ability to detect regional variability in disease risk. Several characteristics of migration are discussed, including some that are not widely known. Because of regional variations in mobility rates and other characteristics of the migration process, there is substantial regional variation in the ability to detect spatial variation in risk. (C) 2002 Elsevier Science Ltd. All rights reserved.
\end{abstract}

Keywords: Migration; Mobility; Disease risk; USA

\section{Introduction}

Residential mobility affects our ability to detect geographic differences in the relative risk of disease. In general, the diffusion of cases will make such detection more difficult. Alternatively stated, the effect of migration will tend to reduce the observed spatial variability in disease rates. It follows that diseases characterized by long latent periods will be more seriously affected than diseases with shorter latent periods.

In this paper, we begin by reviewing past work on the relationship between migration and observed geographic variability in disease rates. We focus primarily on the effects of internal and health-selective migration, and do not review in detail the larger volume of work that exists on disease rate differences between native-born and immigrant populations. In the third section, we note some important aspects of migration in the United States, and indicate the relevance of these characteristics for the detection of geographic differences in disease risk. The fourth section presents both the details of some

\footnotetext{
*Corresponding author. Fax: + 1-716-645-2329.

E-mail addresses: rogerson@acsu.buffalo.edu (P.A. Rogerson), dhan@acsu.buffalo.edu (D. Han).
}

simple models of migration that shed some light on the magnitude of the effects, and an application to cancer data. The final section provides a summary. Our study on the effects of migration is an ecological one in the sense that we assume that data on migration is available by region. Thus, we do not attempt to suggest how causal inferences might be drawn concerning the relationship between individual health and individual migration.

\section{Migration and geographic differences in disease rates}

The effects of migration on geographic variability of disease rates

There have been a large number of studies that have contrasted the disease rate of immigrants with rates in the origin and/or destination country. For example, breast cancer rates are generally lower in Japan than in the United States. Buell (1973) finds an increase in breast cancer rates among Japanese women following migration to the US, suggesting the potential importance of environmental factors. Borras, Snachez, Moreno, Izquierdo and Viladiu (1995) give several references 
pertaining to the study of immigrant populations; for further migrant studies, see Haenszel (1982).

In this paper, we focus on the relationship between internal migration (i.e., subnational, as opposed to international) and the geographic variability of disease rates. If the migration patterns of those with and without the disease are identical, such nonselective mobility will reduce the observed spatial variation in disease risk.

For example, Kliewer (1992) examined the standardized mortality ratios (SMRs) for total, migrant and nonmigrant populations residing in 11 western states. $\mathrm{He}$ found that in-migrants with fairly average rates of stomach cancer mask what turn out to be relatively high rates among nonmigrants in New Mexico. Similarly, inmigrants with average rates of stomach cancer mask the relatively low cancer rates that characterize nonmigrants in California. The effect of migrants was to reduce the interstate variability in mortality rates, since in-migrants from areas of varying mortality risks are mixed with those of the destination nonmigrants. Others have also found that migration reduces geographic variability in observed disease rates (e.g., Kelsey, Mood, \& Acheson, 1968; Bentham 1988). In a study of cancer of the colon and rectum in the United States, Haenszel and Dawson (1965) noted that "classification by current residence may have diluted gradients in risk associated with exposures in urban and rural residences" (with higher incidence in rural regions). In another study, Lanska and Peterson (1995) found that migration had strong effects on the geographical distribution of observed rates of stroke mortality.

These geographical studies of disease often focus upon particular locations and contrast long-term, native nonmigrants with in-migrants. For example, Mancuso and Sterling (1974) focused on all residents of a particular region and examined the relation of place of birth and migration on cancer mortality to evaluate the importance of endemic factors associated with place of birth and influences of the early years of life. An alternative perspective would be to focus upon all of the residents of a given location at some time in the past, and then contrast the rates of nonmigrants with those out-migrants at specific destinations. Data constraints often limit one's ability to adopting this perspective.

To minimize the effects of migration on the assessment of underlying relative risk that characterizes regions, Polissar (1980) recommends (a) study regions that are relatively large, and (b) the study of diseases characterized by relatively short latency periods. The desire for study in large regions needs to be balanced of course by the desire to better understand geographic variability within small study areas. We will return to Polissar's work later in this paper.

While migration is a hindrance to the detection of spatial variability in disease rates, the study of migrant populations has been useful in examining whether rates are more closely associated with place of origin or destination. Haenszel and Dawson used the mortality data for those migrating between urban and rural regions to show that the rate among migrants was more similar to rates at the current residence than to rates at the origin; for stomach cancer, earlier studies had shown that migrants displayed rates more consistent with their state of birth (see also Osmond, Slattery, \& Barker, 1990).

Elford, Phillips, Thomson and Sharper (1990) find, in their study of blood pressure among 7735 men aged 40-59 in Britain, that regional variations are more due to where males spent most of their adult lives than where they grew up. The same authors also study migration and geographic variations in ischaemic heart disease (IHD) in Great Britain, and find that place of residence is a more important determinant than place of birth, and they conclude that it is unlikely that genetic inheritance can explain observed variation. In contrast, Osmond et al. (1990) found that place of birth is a more important determinant for mortality from IHD than place of residence. Strachan, Leon and Dodgeon (1995) conclude that both place of birth and place of residence are related to geographical variations of IHD in England and Wales.

\section{The role of selective migration}

Although the assumption of nonselective migration leads to a decline in the geographic variability of rates, the assumption itself is not always valid, and the health characteristics of migrants may differ from those of nonmigrants. Ellis (1996), for example, finds high rates of out-migration among those diagnosed with AIDS, with the spatial concentration of people with AIDS becoming more concentrated in areas with good-health care facilities. Litwak and Longino (1987) and Meyer and Speare (1985) focus on stages of elderly migration, contrasting amenity-oriented moves early in retirement (dominated by healthy retirees) with assistance-oriented moves later in life. Thus healthy new retirees congregate in popular retirement destinations such as Florida, leaving the less healthy behind in origins such as the Northeastern and Midwestern United States.

Verheij, van de Meen, de Bakker, Groenewegen and Mackenbach (1998) note that people living in urban areas are often found to be less healthy than their rural counterparts. They next ask whether this could be partially due to selective migration. Among 15,895 respondents aged 20-74 in 1991, 613 had moved from an urban to a rural residence, and 191 had moved from a rural to an urban residence, by 1995. Although a bivariate analysis showed movers to be healthier, when demographic and socioeconomic variables were controlled, movers were less healthy, with the exception of 
Table 1

Summary of migration and geographical variations of disease

\begin{tabular}{|c|c|c|c|c|}
\hline Sources & Disease studied & $\begin{array}{l}\text { Geographical } \\
\text { areas }\end{array}$ & Main determinants & Notes \\
\hline $\begin{array}{l}\text { Haenszel and } \\
\text { Dawson (1965) }\end{array}$ & Colon and rectum cancer & US & Place of residence & \\
\hline Kelsey et al. (1968) & Chronic bronchitis & Connecticut, US & $\begin{array}{l}\text { Selective migration by health } \\
\text { status }\end{array}$ & $\begin{array}{l}\text { Importance of length of } \\
\text { residence }\end{array}$ \\
\hline Elford et al. (1989) & $\begin{array}{l}\text { Ischaemic heart disease } \\
\text { (IHD) }\end{array}$ & UK & Place of residence & $\begin{array}{l}\text { No effects of selective } \\
\text { migration }\end{array}$ \\
\hline Britton et al. (1990) & $\begin{array}{l}\text { Malignant neoplasms, } \\
\text { circulatory disease, } \\
\text { respiratory disease }\end{array}$ & $\begin{array}{l}\text { England and } \\
\text { Wales, UK }\end{array}$ & $\begin{array}{l}\text { Selective migration by health } \\
\text { status and distance moved }\end{array}$ & $\begin{array}{l}\text { High mortality of ill-health } \\
\text { and short distance migrants }\end{array}$ \\
\hline Osmond et al. (1990) & $\begin{array}{l}\text { Bronchitis, stroke, IHD, } \\
\text { stomach cancer }\end{array}$ & $\begin{array}{l}\text { England and } \\
\text { Wales, UK }\end{array}$ & Place of birth & \\
\hline Elford et al. (1990) & Blood pressure & UK & Place of residence & \\
\hline Kliewer (1992) & Stomach and colon cancer & $\begin{array}{l}\text { Western States, } \\
\text { US }\end{array}$ & $\begin{array}{l}\text { Significant influence of } \\
\text { migration }\end{array}$ & $\begin{array}{l}\text { Major role of migrant } \\
\text { population }\end{array}$ \\
\hline Strachan et al. (1995) & $\begin{array}{l}\text { Cardiovascular disease } \\
\text { (IHD, Stroke) }\end{array}$ & $\begin{array}{l}\text { England and } \\
\text { Wales, UK }\end{array}$ & $\begin{array}{l}\text { Both place of residence and } \\
\text { birth }\end{array}$ & $\begin{array}{l}\text { No effects of selective } \\
\text { migration }\end{array}$ \\
\hline $\begin{array}{l}\text { Lanska and Peterson } \\
\text { (1995) }\end{array}$ & Stroke & US & $\begin{array}{l}\text { Strong migration effects for } \\
\text { some states, not overall } \\
\text { patterns. }\end{array}$ & Selective elderly migration \\
\hline
\end{tabular}

those in younger age groups. Areas that attract many migrants will become healthier due to demographic and socioeconomic factors. If these factors are accounted for, the opposite is true, except at younger ages.

Another way that areas of high rates may be created through migration is through occupational mobility. Employees exposed to hazardous chemicals at branch plants during the early part of their careers may migrate to management positions at company headquarters. Regions characterized by high rates may emerge at headquarter locations after possibly long latent periods and previous exposures at branch plant locations.

Finally, migration itself may induce a decline in health, due in part to the stress associated with new social environments (Ferraro 1983; Hull 1979; McKinlay 1975). Areas of high in-migration might then, ceteris paribus, have potentially higher rates of morbidity.

Table 1 summarizes some of the previous studies that have focused upon migration and the geographic variability in disease rates.

\section{Four myths about mobility and migration in the United States}

In this section, we examine four myths about mobility and migration in the United States, as well as their consequences for the detection of geographic variability in disease risk. The "myths" range in degree, from those that truly seem to be believed by a large proportion of the population, to those that strike many people as somewhat surprising or counterintuitive.

\section{Myth \#1. We are an increasingly mobile society}

This is perhaps the most pervasive myth of the four. Statements implying that we as a society are increasingly mobile seem to appear almost everywhere. For example, in a summary of the Committee on National Statistics' Study on the Census in the Year 2000 (National Research Council, 1992) one finds the statement:

As people move more frequently, local-area planners and others have greater need for information on migration, such as data on prior residence, distance moved, and reason for moving.

In fact, annual mobility rates (measuring the percentage of the population that changes residence in any given year) have changed little during the last half century, the period over which adequate data exist to address the issue. Fig. 1 depicts the annual mobility rate in the United States over approximately the last $50 \mathrm{yr}$. The mobility rate has fluctuated in the narrow range between $16 \%$ and $21 \%$ during the entire period. If there is any noticeable trend whatsoever, it is a tendency for mobility rates to decline-both during the 1970s and since 1985.

Why have mobility rates remained relatively constant over time? Annual rates of mobility primarily reflect trends in short-distance moving, since the vast majority 


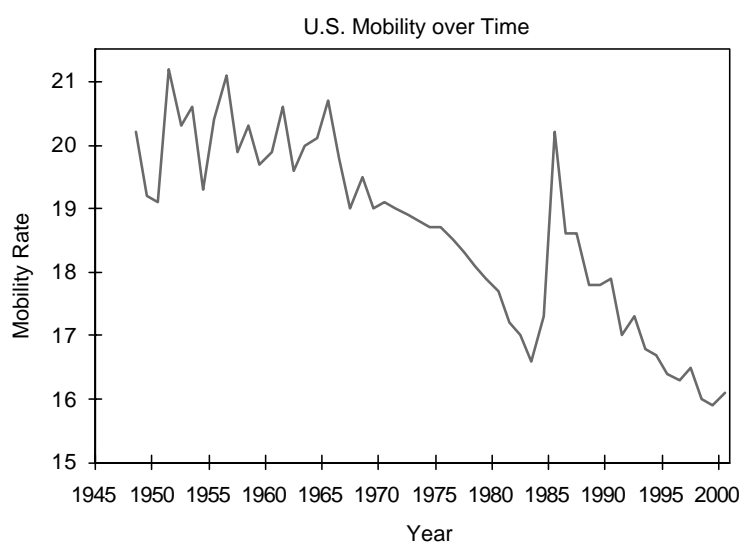

Fig. 1. US mobility over time: 1947-2000.

of all moves are relatively short (see Myth \#2), and thus explanations of the temporal variation in the mobility rate should focus more upon housing markets than upon labor markets. Long (1988) relates an argument by Hawley $(1950,1971)$ that increases in automobile ownership have allowed more extensive commuting, thereby reducing the need for local residential moves brought about by considerations of distance to employment. Yet there is very little evidence for increases in commuting distances.

To lend further insight into recent changes in mobility rates, Rogerson (1987) advanced the hypothesis that mobility rates are negatively correlated with the relative size of the young adult cohort. By generalizing the argument of Easterlin (1980) that generation size is an important determinant of many social and demographic measures, he suggested that large cohorts of young adults would move at relatively small rates, due to the large demand for housing, relative to a given supply. Similarly, small young adult cohorts can be expected to have high mobility rates, since the demand for housing is low relative to the supply. Alternating periods of large generations moving at small rates and small generations moving at high rates would lead to a relatively flat curve for total mobility over time (see Fig. 2). Empirical evidence provided by Rogerson (1987) for the period 1947-1984 supports these suggestions.

Why should we have the perception that we are an increasingly mobile society? Long provides some indirect evidence that if we adopt a longer time perspective (e.g., $100 \mathrm{yr}$, instead of 50), there is in fact some evidence that mobility rates have increased somewhat. But many people holding onto this myth would argue that increases in mobility have taken place during the past $50 \mathrm{yr}$.

The perception of a society characterized by increasing residential mobility may be forged in part by the

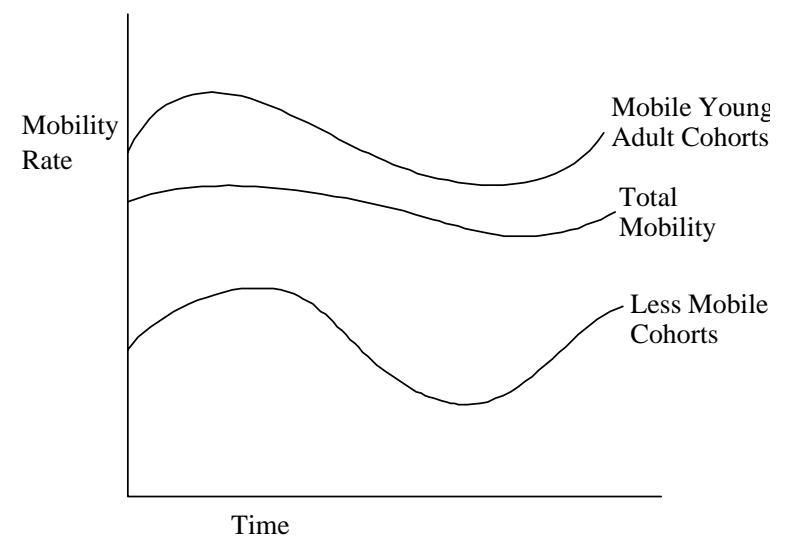

Fig. 2. The mobility rate over time for mobile, less mobile, and total populations.

notion that the ease of traveling long distances made possible by a well-developed transportation network leads to more people venturing further and more often from their homes. Thus we as a society seem "on the go" more often, in terms of the frequency of times we leave home, and in terms of the distances we travel from our homes. But this particular argument is not very strong without supporting evidence. In fact, there is apparently some evidence to the contrary-namely that the proportion of all trips that are long distance trips is actually smaller than it was during the 1950s (see Ayres, 1993). In addition, we all have stories of friends that have, e.g., lived all of their lives in Buffalo, and yet have never been to Niagara Falls, of relatives that have lived in Arizona for $30 \mathrm{yr}$, yet have never seen the Grand Canyon, etc.

A more plausible, explanation for the belief that we are now a more mobile society may be as follows. It is possible that the people who believe most strongly in this myth are those in professional and technical types of occupations. Those who think, comment on, and write about such matters are precisely those who are most likely to have a "fast pace of life", to be occupationally and geographically mobile, to feel the stress of time pressure, to face many competing demands, etc. It is these people that give the myth life, because (a) it may be true for them and/or their network of friends and relatives, and (b) even if it is not true for them individually, the fast pace of life leads to a perception that it must be true.

Consequently, although migration creates difficulties in attempts to find geographic variability in the risk of disease, these are not difficulties that are getting worse over time. Conclusions such as Bentham's (1988) that the implications of migration for the geographical study of disease are "likely to increase with the growing mobility of the population" should be evaluated in light of actual mobility trends. 
Myth \#2. There is a lot of migration that takes place over long distances

Despite the not uncommon perception that when children grow up, they are likely to leave their parents "on their own" by moving a long distance away, the actual evidence indicates that most moves are short. While interstate moves may seem commonplace to many, they usually represent less than $20 \%$ of all moves.

The notion that shorter moves are more frequent than longer ones is perhaps not surprising, and in any event, is consistent with geographic theory, which states that greater interaction takes place over shorter distances than over longer distances. What is surprising is that the median move length is much shorter than most people might imagine - on the order of 5-10 miles in the United States during the 1980s.

Evidence for short median migration distances in the United States comes from two sources. Long, Tucker, and Urton (1988) report the results of an analysis of the 1979 and 1980 Health Interview Surveys, which contain information on distance between current residence and the respondent's residence $3 \mathrm{yr}$ earlier. For those respondents that moved only once during the 3-yr period (a group comprising approximately three-fourths of all who moved at least once during the $3-\mathrm{yr}$ period), they find the median migration distance to be just over $10 \mathrm{~km}$, or 6.2 miles.

Rogerson (1990) takes a quite different approach by combining data on the proportion of people changing their county of residence with the solution to a problem in geometrical probability that dates back to the 18th century. Buffon (1777), in a supplement to a volume he wrote on natural history, posed the following problem: if a needle of known length is tossed at random onto a set of parallel lines separated from one another by a known distance, what is the probability that the needle will come to rest in a position that intersects one of the lines? The answer is a function of the needle length, the distance separating the parallel lines, and the constant $\pi$. During Buffon's time, this led to an interesting empirical means for estimating the value of $\pi$. By repeatedly tossing needles onto the set of lines, and by tallying the number that intersected the parallel lines, the value of $\pi$ could be estimated. The problem was later generalized by Laplace for a square grid (see, e.g., Kendall \& Moran, 1963). But what does this have to do with migration distances? By assuming that the endpoints of the needle correspond to migrant origins and destinations, and that the "average" county shape is square, Rogerson solves for the migration distance (analogous to needle length) in terms of $\pi$, the average county area, and the proportion of migrants that cross county boundaries. He comes up with an estimate of 9.4 miles for median migration distance. Because of various assumptions made by the method, he argues that the estimate may be somewhat high.

Why is the median migration distance so short, and what are the consequences?

As noted above, the majority of moves can be classified as housing adjustments, and these are frequently made over short distances. Many of these moves are related to the life cycles of individuals; events such as marriage, divorce, the addition of a new child to a family, etc. are associated with moves over short distances.

Still another reason for a predominance of shortdistance moves has to do with the availability of information. A general, distance-decay argument may be made that individuals generally have more friends and relatives who live close by, and fewer who live far away. Their knowledge about housing and employment opportunities in other locations is inevitably structured by both their friends and relatives, and by their receipt of information from the media, which also is subject to distance-decay (see, e.g., Nelson 1959; Rogerson \& MacKinnon, 1981).

The fact that most moves are short clearly enhances our ability to detect spatial variability in disease risk. This will especially be true when most move distances are short relative to the size of risk areas defined around point sources of pollution. Stone (1988), in his study of cancer near a nuclear plant, uses parishes with centroids within $17 \mathrm{~km}$ of a nuclear plant, and this is "considered large enough to encompass any excess of risk". Diggle (1990) investigates cancer of the larynx around an industrial incinerator, and obtains significantly raised incidence when point data are smoothed with a Gaussian kernel using a smoothing parameter up to $2 \mathrm{~km}$. Lawson (1993) studies excess bronchitis mortality near a chemical reprocessing plant. He notes that too large an area may lead to a dilution effect, and too small a study area could leave out important effects. In his case, the study area was effectively constrained to a radius of $5 \mathrm{~km}$ by surrounding urban areas.

\section{Myth \#3. There is a negative relationship between in- and out-migration}

Early theories of migration postulated the importance of "push" factors at the origin and "pull" factors at destinations that were instrumental in determining the size of migration flows between places (Lowry 1966). A natural assumption was that variables such as regional unemployment levels would act as push and pull factors simultaneously, in opposite directions. Thus if a county had high unemployment, that could be viewed as a strong push factor and a weak pull factor. Consequently, one might hypothesize that the county would experience high out-migration and low in-migration. Similarly, high wages would lead not only to low 


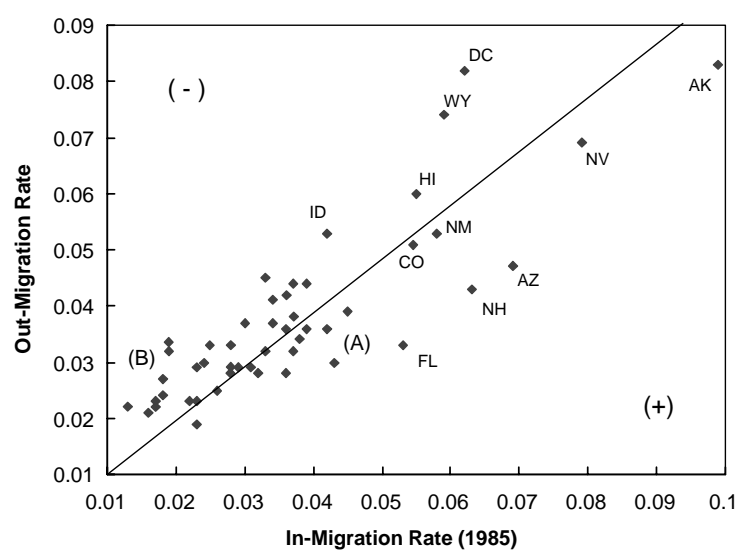

Fig. 3. The relationship between in- and out-migration rates.

out-migration but also to high in-migration. The initial direction hypothesized for the relation between in- and out-migration was therefore negative. However, evidence has accumulated, and explanations set forth, to document and understand an observed positive relation between in- and out-migration (see, for example, the discussion in Plane \& Rogerson, 1994). Fig. 3 depicts the positive relation between in- and out-migration. There are a small number of states with very high rates of inand out-migration. These correspond primarily to states that are in some ways "special"-Alaska, Hawaii, the District of Columbia, and small western states with low population bases. There is a small yet discernible tendency for the remaining states to exhibit net inmigration when their in- and out-migration rates are relatively high (Group A), and to exhibit net outmigration when their in- and out-migration rates are low (Group B). States in group B include Illinois, Kentucky, Louisiana, Michigan, Minnesota, New York, Ohio, Pennsylvania, Wisconsin, and West Virginia. These are states that had relatively stagnant economies during the mid-1980s, and that experienced relatively low labor turnover. States in Group A include Vermont, Delaware, Georgia, Maryland, North Carolina, South Carolina, Virginia, and Washington-primarily growing states that had a high degree of labor turnover. The picture that emerges is one of dynamic, growing regions with high turnover and stagnant regions of net out-migration, characterized by low "turnover" of people.

How may the positive relation between in- and outmigration be explained? Part of the explanation has to do with the fact that a small fraction of the population does most of the migrating. Regions that have many inmigrants are likely to have many out-migrants, because they possess a stock of highly mobile people. A related reason has to do with cumulative inertia (McGinnis 1968); the probability of a move declines with increasing length of residence due to the establishments of social ties, the development of a sense of place, etc. Thus, regions that have high rates of in-migration have high rates of out-migration because they have a stock of highly mobile people, but also because those recent inmigrants have yet to establish strong ties with their new place of residence.

The perhaps surprising relationship between in- and out-migration has the effect of highlighting further any regional differences in our ability to detect geographic variability in disease risk. For those regions with few people moving in, there are also few people moving out, allowing better detection of increased risk than one would have otherwise thought. But in growing regions, not only are possible areas of heightened risk diluted by many in-migrants, they are also diluted by large flows of out-migrants.

\section{Myth \#4. Since we are a relatively homogeneous society, mobility rates probably do not vary much from region to region}

Despite the fact that the US population is highly mobile in comparison with the populations of other countries, there is considerable geographic variability in the degree of mobility. Figs. 4 and 5 are based on 1990 decennial census data, and they display similar geographic patterns. Fig. 4 shows the proportion of the 1990 population reporting a change in their county of residence since 1985. Fig. 5 depicts the fraction of 1990 householders who had moved into their housing unit during the previous year. Mobility rates are almost twice as high in the West as they are in the Midwest and parts of the Northeast. The United States is far from homogeneous with respect to the mobility behavior of its residents.

One consequence of the significant geographic variability in mobility rates is that one should be more able to find any areas of raised risk in the Midwest and Northeast than in the South and West. Not only might the "rustbelt" be characterized as home to more potential putative sources - it might also be easier to find any areas of raised incidence due to low population mobility.

\section{Models of migration and spatial variability in disease rates}

In this section, we present some elementary models to illustrate how we may begin to better characterize and understand the spatial variability in disease rates that is due to migration. We first develop a Markov model to highlight the effects of selective and nonselective migration on the observed regional variability in disease rates. We then give some specific guidelines for using 


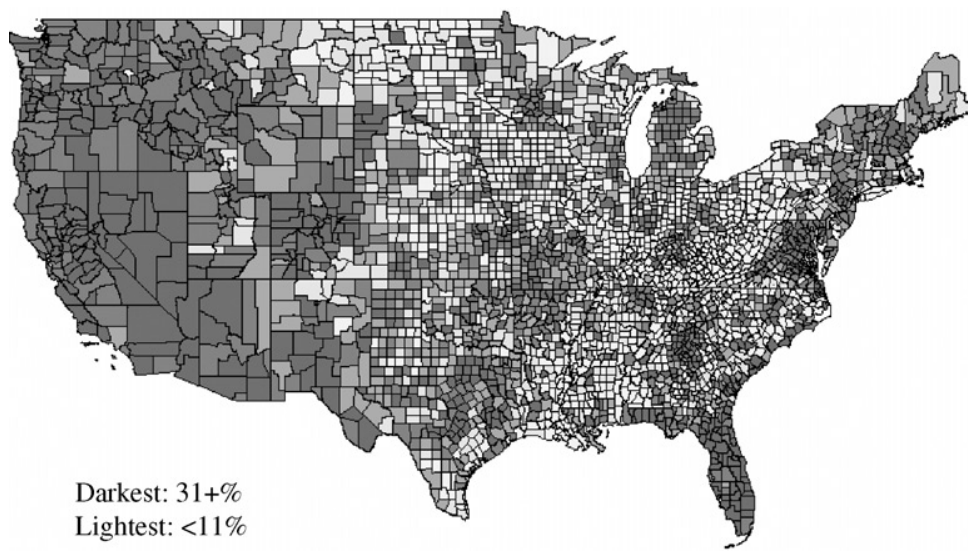

Fig. 4. Percent of population changing county of residence, 1985-90.

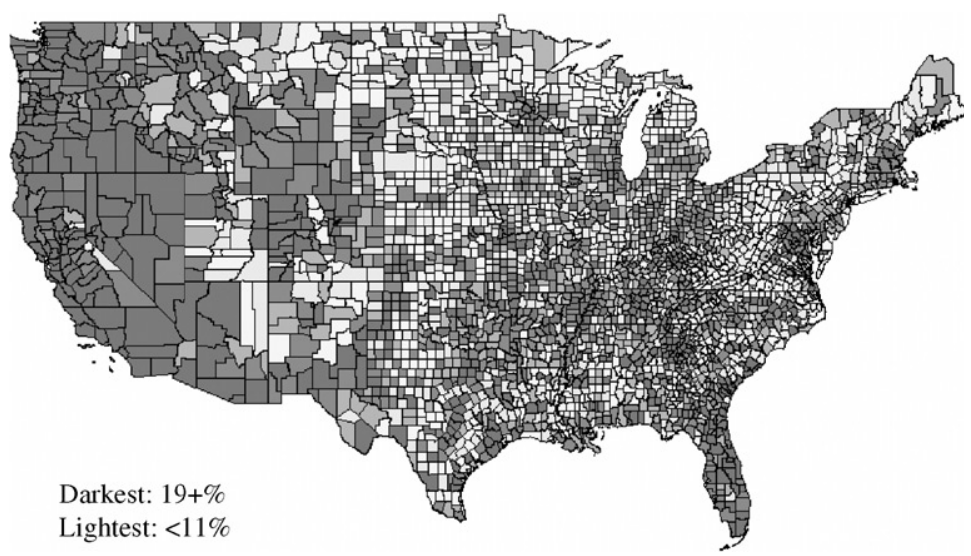

Fig. 5. Percent of householders moving, 1989-90.

Polissar's approach to modeling migration, and provide an illustration using data on lung cancer in New York State.

\section{A Markov model}

Suppose we have a two-region system containing individuals characterized by either the presence or absence of a disease. To examine the effects of migration we can model individuals in the system as a Markov chain with the following four states:

State1 Region A/disease present

State2 Region A/disease absent

State3 Region B/disease present

State4 Region B/disease absent

To examine the effects of mobility, we confine our attention to the simple transition matrix

\begin{tabular}{|c|c|c|c|c|c|}
\hline \multirow{5}{*}{$\mathbf{P}=$ From } & To & 1 & 2 & 3 & 4 \\
\hline & 1 & $1-m_{1}$ & 0 & $m_{1}$ & 0 \\
\hline & 2 & 0 & $1-m_{3}$ & 0 & $m_{3}$ \\
\hline & 3 & $m_{2}$ & 0 & $1-m_{2}$ & 0 \\
\hline & 4 & 0 & $m_{4}$ & 0 & \\
\hline
\end{tabular}

$m_{3}$ and $m_{4}$ are the rates at which those without disease move out of regions $\mathrm{A}$ and $\mathrm{B}$, respectively; $m_{1}$ and $m_{2}$ are the rates at which those with the disease move out of regions $\mathrm{A}$ and $\mathrm{B}$, respectively. Note that in this simple system we are focusing solely on migration, and other dynamic aspects (such as developing disease, latency periods, mortality, etc.) are ignored. In equilibrium, the proportion of people in each state does not change. Letting $\mathbf{x}$ denote the column vector containing the proportion of people in each of the four states:

$\mathbf{x}_{t+1}^{\prime}=\mathbf{x}_{t}^{\prime} \mathbf{P} ; \quad$ for large t. 
This may be solved by writing

$\mathbf{A x}=\mathbf{b}$,

where

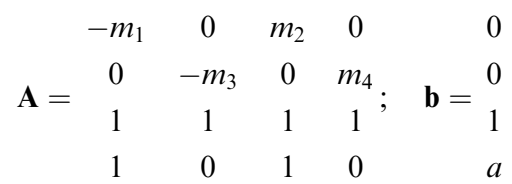

and where $a$ is the proportion of population with disease present. The result is the equilibrium vector of population:

$\mathbf{x}^{\prime}=\left[\frac{a m_{2}}{m_{1}+m_{2}}, \frac{(1-a) m_{4}}{m_{3}+m_{4}}, \frac{a m_{1}}{m_{1}+m_{2}}, \frac{(1-a) m_{3}}{m_{3}+m_{4}}\right]$.

The speed at which equilibrium is approached is negatively related to the largest eigenvalue of $\mathbf{P}$ that is $<1$. The four eigenvalues of $\mathbf{P}$ are $1,1,1-m_{1}-m_{2}$, $1-m_{3}-m_{4}$. Thus, the speed at which equilibrium is approached is determined by the larger of $1-m_{1}-m_{2}$ and $1-m_{3}-m_{4}$, which in turn depends on whichever is smaller, $m_{1}+m_{2}$ or $m_{3}+m_{4}$. If for example $m_{1}+$ $m_{2}<m_{3}+m_{4}$, the speed at which equilibrium is approached depends upon the mobility rates of those with the disease, and the lower the sum of their mobility rates, the longer it will take to reach equilibrium.

The odds against having the disease in the two regions are

$$
\begin{aligned}
& \frac{(1-a)\left(m_{1}+m_{2}\right) m_{4}}{a m_{2}\left(m_{3}+m_{4}\right)} \text { to } 1, \text { in region } \mathrm{A}, \\
& \frac{(1-a)\left(m_{1}+m_{2}\right) m_{3}}{\operatorname{am}_{1}\left(m_{3}+m_{4}\right)} \text { to } 1, \text { in region } \mathrm{B} .
\end{aligned}
$$

The odds ratio that compares the odds in $\mathrm{A}$ with the odds in B may be formed by placing the region A odds in the numerator and the region $\mathrm{B}$ odds in the denominator; the result is simply $\left(m_{1} m_{4} / m_{2} m_{3}\right)$.

In nonselective migration, $m_{1}=m_{3}$ and $m_{2}=m_{4}$, and the long-run incidence rates will be equal across regions. Thus, any initial geographic differences in rates are eliminated via migration. Suppose we have selective migration - perhaps due to better health-care facilities in region B. Thus $m_{1}>m_{3}$ and $m_{2}=m_{4}$. In this example, the odds ratio further simplifies to $m_{1} / m_{3}>1$, implying greater odds against the disease in region $\mathrm{A}$.

Just as Polissar notes, the effect of nonselective migration is to dilute geographic differences in incidence rates. Not surprisingly, the speed of equilibration is a direct function of the magnitude of mobility rates. Thus, as others have noted, regions with small populations will have their "true" incidence rate more greatly affected, since migration rates are higher for them. The shape of regions can also be important. For regions with the same area, migration rates are higher for rectangular regions than for square regions, since people are more likely to live near a border in the latter case (see, e.g., Rogerson
2001). Thus areas characterized by raised risk of disease (e.g., the area around a putative source) are, ceteris paribus, more likely to be found when the area is square than when it is rectangular.

A model based upon Polissar's approach, with an application to cancer data from New York State

Polissar (1980) examined the effects of migration on standardized incidence rates by first defining the standardized ratio

$\mathrm{SR}=\frac{\sum_{i} r_{i} P_{i}}{\sum_{i} s_{i} P_{i}}$,

where $r_{i}$ is the expected disease rate for group $i, s_{i}$ is the expected disease rate for control group $i$, and $P_{i}$ is the population of exposed group $i$. The relative risk of the exposed group is $\rho_{i}=r_{i} / s_{i}$.

Suppose now that a proportion $1-\alpha_{i}$ of the exposed group is really not exposed, due to recent in-migration. The expected rate for the "exposed " group is $\alpha_{i} r_{i}+$ $\left(1-\alpha_{i}\right) s_{i}$, and this should replace the numerator of SR, leading to:

$\mathrm{SR}=1+\frac{\sum_{i} \alpha_{i}\left(\rho_{i}-1\right) s_{i} P_{i}}{\sum_{i} s_{i} P_{i}}$.

When the $\alpha$ 's and $\rho$ 's are equal across groups, this simplifies to

$\mathrm{SR}=1+\alpha(\rho-1)$.

This equation is easily interpretable; if only a proportion of the population has been exposed, then only a fraction of the true excess relative risk would be retained in the estimated risk. Of course it is likely that $\alpha$ also varies with age and other factors; below we indicate how $\alpha$ can be calculated to account for regional differences in age structure.

Polissar notes that effects are greater for diseases with long latent periods, and that for some diseases, risk may sometimes not peak until 30-50 yr after exposure. He also points out that the size of the geographic units matters - long-term residents of large areas are more common than long-term residents of small areas.

He presents two tables. Table 2 displays the percentage of the population with given length of residence for counties. The proportion of population with given duration increases with age, reflecting the decline of mobility rates with age. Polissar gives similar tables for places and states, and the corresponding entries depend upon the size of the geographic area. The larger geographic units generally show higher percentages at given durations of residence. The entries may be taken as the $\alpha_{i}$ 's. Thus diseases with a higher incidence at older ages are more likely to be detected at the location of environmental cause than diseases that strike younger individuals. 
Table 2

Percent of pop with at least $10 / 20 / 30 / 40 \mathrm{yr}$. residence, by age and size of place

\begin{tabular}{|c|c|c|c|c|c|}
\hline & & \multicolumn{4}{|c|}{ Duration of Residence } \\
\hline & & 10 year & 20 year & 30 year & 40 year \\
\hline \multirow[t]{6}{*}{ Age Group } & $18-24$ & $63 \%$ & $25 \%$ & - & - \\
\hline & $25-34$ & $56 \%$ & $42 \%$ & $18 \%$ & - \\
\hline & $35-44$ & $69 \%$ & $40 \%$ & $35 \%$ & $17 \%$ \\
\hline & $45-54$ & $79 \%$ & $59 \%$ & $44 \%$ & $42 \%$ \\
\hline & $55-64$ & $86 \%$ & $73 \%$ & $60 \%$ & 51 \\
\hline & $65+$ & $86 \%$ & $76 \%$ & $67 \%$ & $58 \%$ \\
\hline
\end{tabular}

Source: Polissar (1980).

Table 3

Percentage of original risk retained by length of residence and selected cancer sites (for counties)

\begin{tabular}{lllll}
\hline & \multicolumn{2}{l}{ Length of Residence } & & \\
\cline { 2 - 5 } & 10 year & 20 year & 30 year & 40 year \\
\hline Lung & $84 \%$ & $71 \%$ & $60 \%$ & $51 \%$ \\
Melanoma & $77 \%$ & $59 \%$ & $46 \%$ & $36 \%$ \\
Prostate & $85 \%$ & $75 \%$ & $66 \%$ & $56 \%$ \\
Breast & $81 \%$ & $66 \%$ & $54 \%$ & $45 \%$ \\
All Cancer sites & $82 \%$ & $68 \%$ & $67 \%$ & $48 \%$ \\
\hline
\end{tabular}

Source: Polissar (1980).

Table 3 presents, for selected cancer sites, the percentage of the relative excess risk that is retained in the estimate of relative excess risk; the entries are equal to $100 \sum \alpha_{i} s_{i} P_{i} / \sum s_{i} P_{i}$.

Important conclusions and limitations include (a) earliest exposures are often fairly recent, compared with the latent period, (b) only a small proportion of place populations may be exposed, implying that $\alpha$ could be very small, and (c) statistical power is overestimated if migration is not taken into account.

Here, we illustrate the relation between length of residence and lung cancer incidence rates (age-adjusted) in New York State for the period 1993-1997, to evaluate migration effects on the spatial variability of disease rates. Lung cancer is one of the leading causes of death for both men and women and has a long latency period. In our illustration that follows, we use a latent period of $20 \mathrm{yr}$.

The county-specific fraction of the actual relative excess risk that is retained in the estimated relative excess risk is

$\beta_{\mathrm{C}}=\frac{\sum \alpha_{i} s_{i} P_{i, \mathrm{C}}}{\sum s_{i} P_{i, \mathrm{C}}}$

where the sum is over age groups $i, s_{i}$ is the age-specific lung cancer rate for the state, $P_{i, \mathrm{C}}$ is the age-specific population of the county, and the $\alpha_{i}$ are the age-specific county level values indicating the fraction of population of given age with length of residence $>20 \mathrm{yr}$.

This first step will lead to estimates of relative risk (assumed equal across age groups), adjusted for a county's age distribution. For example, a county with a relatively old age structure will have a relatively higher value of $\beta_{\mathrm{C}}$ and consequently the estimate of relative risk will be quite close to the standardized ratio since

$\rho_{\mathrm{C}}=1+\frac{\mathrm{SR}_{\mathrm{C}}-1}{\beta_{\mathrm{C}}}$.

However, this does not yet correct for county differences in mobility. The $\alpha$ 's used in step 1 are taken from Polissar, and are based upon national, and not county, mobility data. We derived county-specific $\alpha$ 's by

1. finding the estimated proportion of people in the county with length of residence $>20 \mathrm{yr}$, using Polissar's national level $\alpha$ 's

$\alpha_{c}=\sum \alpha_{i} P_{i, c} / \sum P_{i, c}$,

2. finding the actual proportion of householders who resided in their houses for 20 or more years, using 1990 Census data, and

3 . because step (2) is based upon mobility at the level of the household, and step (1) is based on the county, we multiplied the result in (2) by the ratio of the statewide mean of the results in (1) to the statewide 
Table 4

Summary of relative risk retained, standard incidence ratio, and relative risk in New York, by county

\begin{tabular}{|c|c|c|c|}
\hline County & $\begin{array}{l}\text { Percentage of } \\
\text { Risk Retained }\left(\beta_{C}\right)\end{array}$ & $\begin{array}{l}\text { Standard } \\
\text { Incidence } \\
\text { Ratio }\end{array}$ & $\begin{array}{l}\text { Relative } \\
\text { Risk }\end{array}$ \\
\hline Albany & 0.652 & 1.115 & 1.176 \\
\hline Allegany & 0.837 & 1.1 & 1.119 \\
\hline Bronx & 0.52 & 0.851 & 0.714 \\
\hline Broome & 0.77 & 1.088 & 1.114 \\
\hline Cattaraugus & 0.828 & 1.097 & 1.117 \\
\hline Cayuga & 0.793 & 1.106 & 1.134 \\
\hline Chautauqua & 0.782 & 1.019 & 1.024 \\
\hline Chemung & 0.8 & 1.175 & 1.218 \\
\hline Chenango & 0.64 & 1.196 & 1.307 \\
\hline Clinton & 0.637 & 1.259 & 1.407 \\
\hline Columbia & 0.667 & 1.067 & 1.1 \\
\hline Cortland & 0.676 & 1.011 & 1.016 \\
\hline Delaware & 0.706 & 0.949 & 0.927 \\
\hline Dutchess & 0.601 & 1.131 & 1.219 \\
\hline Erie & 0.755 & 1.129 & 1.171 \\
\hline Essex & 0.74 & 1.322 & 1.435 \\
\hline Franklin & 0.719 & 1.342 & 1.475 \\
\hline Fulton & 0.793 & 1.257 & 1.325 \\
\hline Genesee & 0.805 & 1.136 & 1.169 \\
\hline Greene & 0.644 & 1.443 & 1.688 \\
\hline Hamilton & 0.61 & 0.999 & 0.998 \\
\hline Herkimer & 0.79 & 1.034 & 1.043 \\
\hline Jefferson & 0.659 & 1.306 & 1.464 \\
\hline Kings & 0.623 & 0.842 & 0.747 \\
\hline Lewis & 0.807 & 1.191 & 1.237 \\
\hline Livingston & 0.697 & 1.257 & 1.369 \\
\hline Madison & 0.701 & 1.141 & 1.201 \\
\hline Monroe & 0.594 & 1.061 & 1.102 \\
\hline Montgomery & 0.897 & 1.2 & 1.223 \\
\hline Nassau & 0.947 & 0.997 & 0.997 \\
\hline New York & 0.516 & 0.897 & 0.8 \\
\hline Niagara & 0.793 & 1.195 & 1.245 \\
\hline Oneida & 0.837 & 1.122 & 1.146 \\
\hline Onondaga & 0.684 & 1.183 & 1.267 \\
\hline Ontario & 0.598 & 1.121 & 1.202 \\
\hline Orange & 0.598 & 1.252 & 1.42 \\
\hline Orleans & 0.72 & 1.158 & 1.219 \\
\hline Oswego & 0.715 & 1.245 & 1.343 \\
\hline Otsego & 0.724 & 1.109 & 1.151 \\
\hline Putnam & 0.592 & 1.05 & 1.085 \\
\hline Queens & 0.702 & 0.835 & 0.765 \\
\hline Rensselaer & 0.782 & 1.185 & 1.237 \\
\hline Richmond & 0.633 & 1.26 & 1.411 \\
\hline Rockland & 0.674 & 0.982 & 0.973 \\
\hline St. Lawrence & 0.737 & 1.273 & 1.37 \\
\hline Saratoga & 0.55 & 1.182 & 1.331 \\
\hline Schenectady & 0.787 & 1.188 & 1.239 \\
\hline Schoharie & 0.627 & 1.169 & 1.27 \\
\hline Schuyler & 0.665 & 1.13 & 1.195 \\
\hline Seneca & 0.705 & 1.03 & 1.042 \\
\hline Steuben & 0.727 & 1.208 & 1.286 \\
\hline Suffolk & 0.753 & 1.171 & 1.227 \\
\hline Sullivan & 0.619 & 1.387 & 1.625 \\
\hline Tioga & 0.689 & 0.892 & 0.844 \\
\hline
\end{tabular}

Table 4 (continued)

\begin{tabular}{llll}
\hline County & $\begin{array}{l}\text { Percentage of } \\
\text { Risk Retained }\left(\beta_{C}\right)\end{array}$ & $\begin{array}{l}\text { Standard } \\
\text { Incidence } \\
\text { Ratio }\end{array}$ & $\begin{array}{l}\text { Relative } \\
\text { Risk }\end{array}$ \\
\hline Tompkins & 0.481 & 0.947 & 0.89 \\
Ulster & 0.669 & 1.057 & 1.085 \\
Warren & 0.61 & 1.232 & 1.381 \\
Washington & 0.802 & 1.298 & 1.372 \\
Wayne & 0.658 & 1.176 & 1.267 \\
Westchester & 0.66 & 0.888 & 0.83 \\
Wyoming & 0.761 & 0.975 & 0.967 \\
Yates & 0.659 & 1.402 & 1.609 \\
\hline
\end{tabular}

mean of the results in (2). This ratio was equal to $38 \%$ / $24 \%=1.58$. This gives a revised estimate $\alpha_{c}$, of the county-specific proportion of residents who have resided in the county for $>20 \mathrm{yr}$.

4. Finally, the equation for $\beta_{C}$ above is used with Polissar's national level $\alpha_{i}$ 's, each multiplied by the ratio of $\alpha_{C}^{\prime} / \alpha_{C}$.

The results are shown in Table 4 and Fig. 6. Table 4 reveals that the value of $\beta_{C}=\alpha_{(2)}$ ranges from a low of 0.516 in New York County, where mobility is very high, to a high of 0.947 in Nassau County, where mobility is relatively low. Counties with only a small percentage of their residents having a length of residence $>20 \mathrm{yr}$ (such as Orange and Bronx) have revised estimates of relative risk that are quite different from their corresponding standardized ratios. In contrast, counties characterized by a high proportion of long-term residents (such as Fulton and Queens) have revised relative risk estimates that are more similar to the original, uncorrected standardized ratio. In Fig. 6, the letters A and B refer to Fulton and Orange counties, respectively. Despite similar standardized ratios, Orange County's relative risk is relatively higher than Fulton's, and this is a direct consequence of adjusting for the relatively higher mobility that characterizes Orange County. The letters $\mathrm{C}$ and D refer to Bronx and Queens counties, respectively. Both of these counties have lung cancer rates that are lower than the statewide rate. Despite a slightly higher standardized ratio, the relative risk in Bronx County is actually lower when compared with Queens County. This is attributable to the higher mobility that characterizes Bronx County. In general, regions with high mobility will be located relatively far from the $45^{\circ}$ line, while more stable regions lie close to it. Finally, note that the plotted points intersect the $45^{\circ}$ at $\mathrm{SR}=\rho=1$. When $\mathrm{SR}=1$, there is no effect of migration on estimates of relative risk. Thus, regions characterized by relatively extreme values of SR are also those that have actual relative risks that are most affected by migration. 
Comparison of SIR and RR

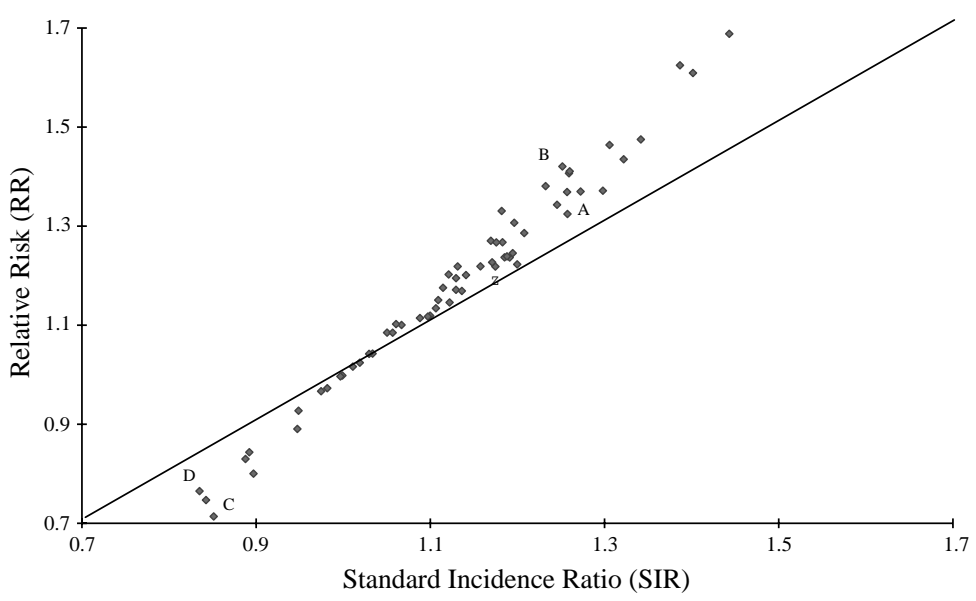

Fig. 6. Comparison of standardized incidence ratios and relative risk.

\section{Conclusion}

In the last section of the paper, we have suggested a method to model migration and its effects on disease rates, and we have illustrated it using New York State lung cancer data.

As Rigby and Gatrell (2000) note, one alternative approach for treating migration in the geographical study of disease is to "exclude cases based on length of residence". For example, Timander and McLafferty (1998) use only those cases where residents lived at their address for $30 \mathrm{yr}$ or more, in a study of breast cancer on Long Island. Rigby and Gatrell rightly point out that this is a somewhat ad hoc and arbitrary approach, and can have a serious effect on the completeness of the dataset. Another alternative would be to consider the use of model migration schedules (e.g., Rogers, Willekens, \& Ledent, 1983), whereby individual migration histories could be imputed on the basis of factors such as age and sex.

It is well known that migration can have a serious effect on the detection of geographical differences in disease risk. In this paper, we have discussed four lesser-known aspects of migration, as well as their effects on the detection of geographic variability in risk. Mobility rates are not increasing, and in addition, most moves are short - the consequence of both of these tendencies is to ensure that the deleterious effect of migration on detection of areas of high risk is not getting worse over time. However, we have also seen that (a) areas of high in-migration are also characterized by high out-migration, and (b) there is substantial regional variation in mobility rates. These latter two aspects of migration in the United States are prominent ones, and they give rise to substantial regional differ- ences in the ability to detect geographic differences in disease risk.

\section{Acknowledgements}

This paper was made possible by grant number $1 \mathrm{R} 01$ ES09816-01 from the National Institute of Environmental Health Sciences, National Institutes of Health. Its contents are solely the responsibility of the authors and do not necessarily represent the official views of the sponsoring agencies. We also acknowledge the helpful comments from two anonymous referees.

\section{References}

Ayres, E. (1993). Breaking away. World Watch, 6, 10-18.

Bentham, G. (1988). Migration and morbidity: implications for geographical studies of diseases. Social Science and Medicine, 26, 49-54.

Borras, J. P., Snachez, V. Z., Moreno, V., Izquierdo, A., \& Viladiu, P. (1995). Cervical cancer: incidence and survival in migrants within Spain. Journal of Epidemiology and Community Health, 49, 153-157.

Britton, M., Goldblatt, P., Jones, D. R., \& Rosato, M. (1990). The influence of migration on geographical variation in mortality. In: M. Britton, (Ed.), Mortality and geography: a review in the mid-1980s, England and Wales, OPCS Series DS No. 9. (pp. 80-94). London: HMSO.

Buell, P. (1973). Changing incidence of breast cancer in Japanese-American women. Journal of the National Cancer Institute, 51, 1479-1483.

Buffon, G. L. (1777). Essai d'arithmetique morale. Supplement a l'histoire naturelle, 4. 
Diggle, P. (1990). A point process modelling approach to raised incidence of a rare phenomenon in the vicinity of a prespecified point. Journal of the Royal Statistical Society Series A, 153, 349-362.

Easterlin, R. (1980). Birth and fortune: the impact of numbers on personal welfare. New York: Basic Books.

Elford, J., Phillips, A., Thomson, A. G., \& Sharper, A. G. (1989). Migration and geographic variations in ischaemic heart disease in GB. Lancet, 1(8634), 343-346.

Elford, J., Phillips, A., Thomson, A. G., \& Sharper, A. G. (1990). Migration and geographic variations in blood pressure in Britain. British Medical Journal, 300, 291-295.

Ellis, M. (1996). The postdiagnosis of people with AIDS. Environment and Planning A, 28, 999-1017.

Ferraro, K. F. (1983). The health consequences of relocation among the aged in the community. Journal of Gerontology, $38,90-96$.

Haenszel, W. (1982). Migrant studies. In D. Schottenfeld, \& J. D. Fraumeni (Eds.), Cancer epidemiology and prevention (pp. 194-207). Philadelphia, PA: W.B. Saunders.

Haenszel, W., \& Dawson, E. A. (1965). A note on the mortality from cancer of the colon and rectum in the United States. Cancer, 18, 262-272.

Hawley, A. (1950). Human ecology: a theory of community structure. New York: Ronald Press.

Hawley, A. (1971). Urban society: an ecological approach. New York: Ronald Press.

Hull, D. (1979). Migration, adaptation, and illness: a review. Social Science and Medicine, 13A, 25-36.

Kelsey, J. L., Mood, E. W., \& Acheson, R. M. (1968). Population mobility and epidemiology of chronic bronchitis in Connecticut. Archives of Environmental Health, 16, 853-861.

Kendall, M. G., \& Moran, P. A. P. (1963). Geometrical probability. New York: Methuen.

Kliewer, E. V. (1992). Influence of migrants on regional variations of stomach and colon cancer mortality in the western United States. International Journal of Epidemiology, 21, 442-449.

Lanska, D. J., \& Peterson, P. M. (1995). Effects of interstate migration on the geographic distribution of stroke mortality in the United States. Stroke, 26(4), 554-561.

Lawson, A. (1993). On the analysis of mortality events associated with a prespecified fixed point. Journal of the Royal Statistical Society Series A, 156, 363-377.

Litwak, E., \& Longino, C. F. (1987). Migration patterns among the elderly: a developmental perspective. The Gerontologist, 27, 266-272.

Long, L. (1988). Migration and residential mobility in the United States. New York: Russell Sage Foundation.

Long, L., Tucker, C. J., \& Urton, W. L. (1988). Migration distances: an international comparison. Demography, 25, 633-640.

Lowry, I. (1966). Migration and metropolitan growth. San Francisco: Chandler.

Mancuso, T. F., \& Sterling, T. D. (1974). Relation of place of birth and migration in cancer mortality in the US: a study of
Ohio residents, 1959-67. Journal of Chronic Disease, 27, 459-474.

McGinnis, R. (1968). A stochastic model of social mobility. American Sociological Review, 23, 712-722.

McKinlay, J. B. (1975). Some issues associated with migration, health status, and the use of health services. Journal of Chronic Diseases, 28, 579-592.

Meyer, J. W., \& Speare, A. (1985). Distinctive elderly mobility: types and determinants. Economic Geography, 61, 79-88.

National Research Council. (1992). Committee on National Statistics. Study on the Census in the Year 2000. Commission on Behavioral and Social Sciences and Education, Washington, DC.

Nelson, P. (1959). Migration, real income, and information. Journal of Regional Science, 1, 43-74.

Osmond, C., Slattery, J. M., \& Barker, D. J. P. (1990). Mortality by place of birth. In Britton, M. (Ed.), Mortality and geography: a review in the mid-1980s, England and Wales. OPCS Series DS No. 9. (pp. 96-101). London: HMSO.

Plane, D., \& Rogerson, P. (1994). The geographical analysis of population: with applications to planning and business. New York: Wiley.

Polissar, L. (1980). The effect of migration on comparison of disease rates in geographic studies in the United States. American Journal of Epidemiology, 111, 175-182.

Rigby, J. E., \& Gatrell, A. C. (2000). Spatial patterns in breast cancer incidence in north-west Lancashire. Area, 32, $71-78$.

Rogers, A., Willekens, F., \& Ledent, J. (1983). Migration and settlement: a multiregional comparative study. Environment and Planning A, 15, 1585-1612.

Rogerson, P. (1987). Changes in US national mobility levels. The Professional Geographer, 39, 344-351.

Rogerson, P. (1990). Buffon's needle and the estimation of migration distances. Mathematical Population Studies, 2, 229-238

Rogerson, P. (2001). Statistical methods for geography. London: Sage Publications.

Rogerson, P., \& MacKinnon, R. (1981). Interregional migration models with source and interaction information. Environment and Planning A, 14, 445-454.

Stone, R. A. (1988). Investigations of excess environmental risks around putative sources: statistical problems and a proposed test. Statistics in Medicine, 7, 649-660.

Strachan, D. P., Leon, D. A., \& Dodgeon, B. (1995). Mortality from cardiovascular disease among interregional migrants in England and Wales. British Medical Journal, 310, 423-427.

Timander, L. M., \& McLafferty, S. (1998). Breast cancer in West Islip, NY: a spatial clustering analysis with covariates. Social Science and Medicine, 46, 1623-1636.

Verheij, R. A., van de Meen, H. D., de Bakker, D. H., Groenewegen, P. P., \& Mackenbach, J. P. (1998). Urbanrural variations in health in the Netherlands? Does selective migration play a part? Journal of Epidemiology and Community Health, 52, 487-493. 